dehiscence of the prosthesis only in cases of mucoid degeneration. ${ }^{3}$ Recently another case has been described by L. J. McCarthy and P. L. Wolf in a man aged $70^{4}$ who had had a murmur for at least 20 years previously. He was admitted in heart failure with severe mitral incompetence, and a valvular replacement was performed. He died four days later with a cerebral infarct. The excised mitral valve contained pools of blue mucoid material.

Mucoid degeneration of the heart valves has long been recognized as an association of Marfan's syndrome, ${ }^{15}$ but it is much less common than Erdheim's cystic medionecrosis of the aorta, which predisposes to dissecting aneurysm. In some of the cases of isolated mucoid degeneration there have been stigmata of Martin's sydrome, ${ }^{15}$ notably some skeletal manifestations. These presumably represent a forme fruste of the syndrome. In many others, including that of McCarthy and Wolf, there were no such stigmata, and the lesion appears to be a localized disorder of the valvular connective tissue.

This condition is not as uncommon as would appear from its infrequent description. In one series of 140 patients who had had one or more valves excised between the years 1961 and 1967 there were 21 cases of mucoid degeneration. ${ }^{6}$ It is also a predisposing factor to infective endocarditis. ${ }^{1}$ These considerations and the troubles that may follow valvular replacement make mucoid degeneration a lesion to be watched for by surgeon and pathologist.

' Read, R. C., Thal, A. P., and Wendt, V. E., Circulation, 1965, 32, 897. 2 Castleman, B., and McNeely, B. U., New England fournal of Medicine, $1967,277,92$.

3 Wolf, P. L., and Read, R. C., American fournal of Clinical Pathology, $1964,42,518$.

- McCarthy, L. J., and Wolf, P. L., American fournal of Clinical Pathology, 1970, 54, 852.

s McKusick, V. A., Heritable Disorders of Connective Tissue, 3rd edn, p. 85. St. Louis, Mosby, 1966

- Frable, W. J., American fournal of Clinical Pathology, 1969, 52, 84.

\section{Ocular Bobbing}

In the Brave New Medical World of double-blind trials and parameters we are apt to look back wistfully to those halcyon days when simple clinical observation was all that mattered, when the wiseacre at the bedside could notice something out of the ordinary, and then immortalize his finding (and often his name) for posterity. And around the eyes, which are so often the signpost to the body's ills, a host of signs and syndromes (with unforgettable or all too easily forgettable eponyms) have accumulated over the last decades. So the recent description of "ocular bobbing" is an echo of this hallowed tradition.

Ocular bobbing is a distinctive, spontaneous eye movement having an abrupt, spontaneous downward jerk of the eyes and a slow return to the mid-position. It is readily distinguishable from the down-beating nystagmus (with the opposite slow-fast sequence) and the pendular movements of an ocular myoclonus. C. M. Fisher ${ }^{1}$ first described it ten years ago in patients with paralysis of horizontal conjugate eye movements. Four subsequent observers have added to the literature, which now musters 25 cases. The latest report, by $J$. $O$. Susac and colleagues ${ }^{2}$ subdivides bobbing into the "typical" form, "monocular" form (having a coexisting ocular palsy), and an "atypical" form, and will doubtless help to establish the condition as a clinical entity for the textbooks and examinations of the future.
The importance of this curious anomaly remains uncertain. It is usually noted in patients who are moribund (from intrapontine haemorrhage or similarly grave disorders) if not actually in their terminal coma, and its mechanism is obscure. But further cases will surely be reported, and so we may learn more about it. Any reminder of the value of plain clinical observation must always be welcome.

1 Fisher, C. M., in Pathogenesis and Treatment of Cerebrovascular Disease. A symposium edited by W. S. Fields. Illinois, Thomas, 1961 . Susac, J. O., Hoyt, W. F., Daroff, R. B., and Lawrence, W., foumal of Neurology, Neurosurgery and Psychiatry, 1970, 33, 771.'

\section{Dermatitis Herpetiformis}

Job "took a potsherd to scrape himself withal." Though we may suspect, in view of his many troubles, that he was suffering from disseminated neurodermatitis with severe secondary infection, dermatitis herpetiformis has been suggested as a possible diagnosis. This too may have been the disease that caused Marat to spend so much of his time in the bath where Charlotte Corday stabbed him.

Dermatitis herpetiformis is a comparatively uncommon skin disease, but it deserves attention because of its favourable response to certain drugs and because the mucosa of the small intestine is often atrophic. Itch is the predominant symptom. It can reach an unbearable intensity, destroy sleep, embarrass its victim by making him scratch in public, and render him miserable and demoralized. The eruption appears in symmetrical patches-for example, over the shoulders, buttocks, elbows, and thighs. Within each patch are commonly a variety of lesions-weals, papules, vesicles, or bullae, scratch marks (often complicated by secondary pyogenic infection), pigmentation, and the scars of healed lesions. It is unusual to find a patient with dermatitis herpetiformis in whom vesicles or bullae do not appear at some time during the course of his disease. In children the blisters can be large and grouped round the mouth and genital region.

A common error in diagnosis is scabies. Other infestations must also be excluded, and onchocerciasis is a possibility in patients who have lived in those parts of the tropics where it is endemic.

Dapsone or sulphapyridine by mouth will suppress the lesions within a week, but they will recur when the dose falls below an optimal level that must be determined for each patient. Satisfactory control depends on carefully supervised treatment. The suppressive dose usually falls gradually over a course of years, and it may be possible to stop treatment altogether eventually. Though inorganic arsenic-for example, Fowler's solution-also clears the lesions, it is unsafe to give because of the risk of long-delayed serious effects such as cirrhosis of the liver and carcinoma. If the patient does not respond to treatment, the diagnosis should be reviewed with special reference to chronic liver or kidney disease, reticulosis, occult carcinoma, or disseminated neurodermatitis.

The aetiology of the disease remains obscure. The suppressive action of sulphapyridine does not depend on its antibacterial activity. The eruption will reappear promptly after years of suppression if the treatment is stopped, and it is interesting that under these circumstances the blisters may be unusually large. These drugs may block some metabolic pathway on which the eruption of lesions depends. The discovery that enteropathy can accompany dermatitis herpeti- 